Theories \& Applications, the International Edition

Printed Version : (ISSN 2090-5262)

Online Version : (ISSN 2090-5270)

July 2014, Volume 4, No. 2 Pages (93 - 98)

\title{
Effect of Core Strength Training on Power and Dynamic Balance among Child Athletes.
}

\section{Fatma Abdelbaky}

Faculty of Physical Education, Helwan University, Egypt.

\section{Amany Ahmed}

Faculty of Physical Education, Helwan University, Egypt.

\begin{abstract}
The "IAAF Kids Athletics" program aims to ensure a steady and sustainable policy of athletics development. The program is not intended only for clubs and member federations but also for schools and all institutions that are interested in the wellbeing of children. The IAAF seeks to popularize athletics in six areas through several competitions called "A Team Event for Children," comprising three event groups: Sprinting/Running Event Group, Jumping Event Group, and Throwing Event Group. Three age categories are targeted by the program: 7-8 years, 9-10 years, and 11-12 years. Core strength consists of the motor control and muscular capacity of the lumbopelvic-hip complex. The aim of the present study was to determine the effect of a 10-week core strength training program on dynamic balance, power, and program skills among child athletics. Twenty children were divided into two groups. The experimental group consisted of 10 children in the 7-8 year age group. The subjects in this group underwent a core strength training program that consisted of body weight exercises, the Swiss ball, and the medicine ball for 10 weeks. The control group consisted of 10 children who were the same age as the experimental group. Height, weight, power, dynamic balance, and training age were assessed. All of the subjects were free of any disorders known to affect performance, such as bone fractures, osteoporosis, diabetes, and cardiovascular disease. All of the participants were fully informed of the aims of the study and gave their voluntary consent before participation. The measurement procedures were consistent with ethical human experimentation. All statistical analyses were performed using SPSS software. The results are reported as means and standard deviations. Differences between the two groups are reported as the mean difference $\pm 95 \%$ confidence intervals. Student's t-test for independent samples was used to determine differences in the parameters between the two groups. The results revealed significant increases in dynamic balance, power, and program skills between the pre- and post-measures in the experimental group. In conclusion, a 10-week core strength program can improve physical skills and dynamic balance in child athletics.
\end{abstract}

Keywords: Core strength; Dynamic balance; Power; Child Athletics.

\section{Introduction}

$\mathrm{I}$ 2005, the IAAF created a global athletics policy for youths from 7 to 15 years of age. This policy has two objectives: to make athletics the most practiced individual event in school worldwide and enable children from federations and others to prepare for their future in athletics in the most efficient way possible. This approach hinges on forming competitions that are appropriate for all age categories and the institutions that implement this program.

"IAAF Kids' Athletics" is intended to bring excitement to engaging in athletics. New events and innovative organizations enable children to discover basic activities (e.g., sprinting, endurance running, jumping, and throwing/putting) in just about any location (e.g., stadiums, playgrounds, gymnasiums, and any available sports area). The athletics games will provide children the opportunity to make the most of the beneficial practice of athletics in terms of health, education, and self-fulfillment.
As a normal child develops, his core muscle strength is established through repetitive active movements and movements against gravity. The child engages in small components of these movements before combining them to achieve a functional core. This functional, stable core serves as the foundation for coordinated movement of the child's arms and legs (Janice, 2011).

The core is defined as the lumbo-pelvic hip complex. It is where our center of gravity is located and where movements of the body originate. An efficient core allows for optimal acceleration, deceleration, and stabilization of the entire kinetic chain during functional exercise. The core needs to be trained appropriately to efficiently distribute weight, absorb force, and transfer ground reaction forces during functional movements.

Classic literature classified the musculature of the core as being controlled by "local" and "global" muscular systems (Bergmark, 1989). The "local" system consists of all of the muscles that originate and insert at the vertebrae, with the exception of the psoas muscles that flex the hip joints 
(Bergmark, 1989). The role of the "local" system is to control the curvature of the lumbar spine, aid in the coordination and control of motion segments, and provide sagittal and lateral stiffness to maintain mechanical spinal stability. The "global" system acts to transfer forces from the thoracic cage and pelvis to the extremities (Bergmark, 1989). The muscles of the "global" system have longer moment arms of force and larger cross-sectional areas than the muscles of the "local" system, making them ideal for force production (Arokoski et al., 1999).

Core training programs include processes that target muscular strength and motor control of the core musculature (Nadler et al., 2002) Core strengthening exercises are very popular in rehabilitation programs despite little scientific evidence of their efficacy in improving subsequent performance (Stanton, et al., 2004; Cosio-Lima et al., 2003; Tse et al., 2005), although some research has suggested that numerous methods can enhance neuromuscular control. These include joint stability exercises (Behm et al., 2002), contraction exercises (i.e., concentric, eccentric, and isometric; Pollock et al., 1989), balance training (CosioLima et al., 2003), perturbation (i.e., proprioceptive) training (Lewis \& Hawke, 1983; Carriere, 1999), plyometric (i.e., jump) exercises (i.e., plyometric training that emphasizes the loading of joints and muscles eccentrically before unloading concentric activity; Axler and McGill, 1997), and sportspecific skill training (Lehman, 2006). In the field of physiotherapy, proprioceptive training is believed to be important. Consequently, some programs use methods and exercises that challenge proprioception using equipment such as wobble boards, roller boards, discs, and Swiss balls.

Comerford (2007) believes that performing both low- and high-load threshold training is important to train core stability and strength. Comerford (2008) identified the following sub-areas of core training that all need to be included when training core stability and strength:

1. Motor control stability: low-threshold stability in which the central nervous system modulates the efficient integration and low-threshold recruitment of local and global muscle systems.

2. Core strength training: high-threshold and overload training of the global stabilizer muscle system, leading to hypertrophy as an adaptation to overload training.

According to Nick Evangelista (1996), most coaches do not focus on the development of muscle strength, believing that strength training may negatively affect speed performance, and subjecting muscles to strength training may lead to muscle hypertrophy and thus adversely affect flexibility. Additionally, some athletics coaches focus on the development of the physical demands of sports together with the development of skills.

The aim of the present study was to determine the effects of a 10-week core strength training program on dynamic balance, power, and program skills in child athletics.

\section{Material and Methods}

\section{Participants}

Twenty children were divided into two groups. The experimental group consisted of 10 children in the 7-8 year age group. The subjects in this group underwent a core strength training program that consisted of body weight exercises, the Swiss ball, and the medicine ball for 10 weeks. The control group consisted of 10 children who were the same age as the experimental group. Height, weight, power, dynamic balance, and training age were assessed. All of the subjects were free from any disorders known to affect performance, such as bone fractures, osteoporosis, diabetes, and cardiovascular disease. All of the participants were fully informed about the aims of the study and gave their voluntary consent before participation. The measurement procedures were consistent with ethical human experimentation.

\section{Procedures}

Subjects were assessed before and after the ten-week training program. All measurements were taken one week before and after training at the same time of day. Tests followed a general warm-up that consisted of running, calisthenics, and stretching.

\section{Core Muscle Strength and Stability Test (CST)}

The objective of this evaluation was to monitor the development and improvement of an athlete's core strength and endurance over time. The test consists of the following:

- Flat surface.

- Mat.

- Watch or clock with second counter.

- Conduct the test.

- Position the watch or clock where it can easily be seen.

- Start in the Plank Exercise Position (elbows on the ground). Hold for $60 \mathrm{~s}$.

- Lift right arm off the ground. Hold for $15 \mathrm{~s}$.

- Return right arm to the ground and lift left arm off the ground. Hold for $15 \mathrm{~s}$.

- Return left arm to the ground and lift right leg off the ground. Hold for $15 \mathrm{~s}$.

- Return right leg to the ground and lift left leg off the ground. Hold for $15 \mathrm{~s}$.

- Lift left leg and right arm off the ground. Hold for $15 \mathrm{~s}$.

- Return left leg and right arm to the ground.

- Lift right leg and left arm off the ground. Hold for $15 \mathrm{~s}$. 
- Return to Plank Exercise Position (elbows on the ground)Treadmill

\section{Static Strength Test (LS) (BS)}

A back dynamometer was used to measure static leg strength. The subjects stood on the dynamometer platform and crouched to the desired leg bend position with a dynamometer strapped around the waist. At the prescribed time, the subjects exerted maximum force straight upward by extending their legs. They kept their backs straight, with the head erect and chest high. The subjects underwent three trials, and the best score was used. The subjects were allowed to rest between trials.

\section{Standing Long Jump (SLJ)}

The subjects stood behind a line marked on the ground with the feet slightly apart. A $2 \mathrm{ft}$ take-off and landing was used, while swinging the arms and bending the knees to provide forward drive. The subjects attempted to jump as far as possible, landing on both feet without falling backwards. Three attempts were allowed.

\section{Seated Medicine Ball Throw (SMBT)}

The subjects stood with their back to a wall on a mat that faced the area to which the ball was to be thrown, with the feet extended and slightly apart. The ball was held with both hands on the side and slightly behind the center. The ball was brought to the chest and then thrown vigorously out as far as possible. The back was to remain in contact with the wall at all times. Three attempts were allowed. The distance from the wall to where the ball landed was recorded. The measurement was recorded to the nearest $10 \mathrm{~cm}$. The best result of three throws was used.

\section{Flying start $30 \mathrm{~m}$ sprint test}

A $40 \mathrm{~m}$ run was marked with a "timing" start line $10 \mathrm{~m}$ into the run. From a standing start, the subjects ran the $40 \mathrm{~m}$ distance as quickly as possible. The run was timed from 10 $\mathrm{m}$ line to the $40 \mathrm{~m}$ line to obtain a flying $30 \mathrm{~m}$ time.

\section{Dynamic Balance Test using Star Excursion Balance Test}

- The subjects were instructed to stand in the center of a star grid and maintain a single-leg stance while reaching with the opposite leg to touch as far as possible along a chosen excursion.

- The subjects were instructed to touch the farthest point as possible as lightly as possible along a chosen excursion with the most distal part of their reach foot.

- The subjects were instructed to return to a bilateral stance while maintaining their balance.
- The subjects were instructed to perform six practice trials in each of the eight excursions with a $10 \mathrm{~s}$ rest between each excursion.

- After a $1 \mathrm{~min}$ rest following the last practice trial, the test began.

- Three trials were performed in each of the eight excursions with a $10 \mathrm{~s}$ rest between each excursion.

- The trials were discarded and repeated if the reach foot was used to provide considerable support when touching the ground, if the subject's stance foot was lifted from the center of the star grid, or if the subject was not able to maintain balance at any point in the trial.

- The average scores for each excursion were recorded as the subject's dynamic balance score.

\section{Core strengthening protocol}

In athletic endeavors, muscle endurance appears to be more important than pure muscle strength (Nadler et al., 2002). The overload principle advocated in sports medicine is a nemesis for the back. Progressive resistance strengthening of some core muscles, particularly the lumbar extensors, may be unsafe for the back.

Functional progression is the most important stage in a corestrengthening program. A thorough history of functional activities should be taken to individualize this part of the program.

The present research adopted the application of core strength training based on the following: (1) the focus was on strengthening the muscles and the stability of the center, (2) at the end of the module, the training given for muscle relaxation was extended to return to normal, (3) training method used, you see a high intensity training system using a ring, (4) loads within the circuit training occur through changes between the time of performance and comfort between the exercise and also between groups. and (5) the circuit includes six exercises in three to five groups. Table 1 shows Core Exercise Progression.

\section{Statistical Analysis}

All statistical analyses were calculated by the SPSS statistical package. The results are reported as means and standard deviations (SD). Differences between two groups are reported as mean difference $\pm 95 \%$ confidence intervals (mean diff $\pm 95 \% \mathrm{CI}$ ). Student's t-tests for independent samples were used to determine the differences in physical variables between the two groups. A P-value $<0.05$ was considered statistically significant. 
Results

Table 1

Core Exercise Progression.

\begin{tabular}{|c|c|}
\hline Base position & Supine with knees bent and feet on floor \\
\hline cue & Spine stabilized with "navel to spine" \\
\hline Level 0.3 & Base position with one foot lifted \\
\hline Level 0.4 & Base position with one knee held to chest and other foot lifted \\
\hline Level 0.5 & Base position with one knee held lightly to chest and other foot lifted \\
\hline Level 1A & Knee to chest $\left(90^{\circ}\right.$ hip flexion) held actively and other foot lifted \\
\hline Level 1B & Knee to chest $\left(90^{\circ}\right.$ hip flexion) held actively and other foot lifted \\
\hline Level 2 & Knee to chest $\left(90^{\circ}\right.$ hip flexion) held actively and other foot lifted and slid on ground \\
\hline Level 3 & Knee to chest $\left(90^{\circ}\right.$ hip flexion) held actively and other foot lifted and not slid on ground \\
\hline Level 4 & Bilateral heel slides \\
\hline Level 5 & Bilateral leg lifts to $90^{\circ}$ \\
\hline
\end{tabular}

Table 1 shows Core Exercise Progression.

Table 2

Mean \pm SD and Descriptive statistics between experimental and control groups in SLJ, SMBT, CST, LS, and BS.

\begin{tabular}{|c|c|c|c|c|c|}
\hline \multirow{2}{*}{ Variables } & \multicolumn{2}{|c|}{ Experimental group } & \multicolumn{2}{|c|}{ Control group } & \multirow{2}{*}{ T sign. } \\
\hline & Pre & Post & Pre & Post & \\
\hline SLJ $(\mathbf{c m})$ & $169.25 \pm 5.06$ & $176.00 \pm 5.11$ & $168.92 \pm 4.87$ & $171.43 \pm 5.11$ & Sign. \\
\hline SMBT (meter) & $6.23 \pm 0.16$ & $7.16 \pm 0.54$ & $6.21 \pm 0.39$ & $6.78 \pm 0.47$ & Sign. \\
\hline CST (Degree) & $5.31 \pm 0.08$ & $7.11 \pm 0.15$ & $5.22 \pm 0.23$ & $5.39 \pm 0.26$ & Sign. \\
\hline LS (KG) & $59.42 \pm 3.84$ & $62.22 \pm 4.89$ & $59.25 \pm 4.26$ & $60.74 \pm 4.38$ & Sign. \\
\hline BS (KG) & $37.51 \pm 4.26^{*}$ & 45.22 \pm 3.79 & $38.05 \pm 4.37$ & $40.31 \pm 3.28$ & Sign. \\
\hline 30m Sprint & $5.61 \pm 0.03$ & $5.28 \pm 0.09$ & $5.65 \pm 0.08$ & $5.42 \pm 0.06$ & Sign. \\
\hline
\end{tabular}

Table 2 shows statistically significant differences in the post-measurements between the experimental and control groups in all of the physical variables.

Table 3

Descriptive statistics for the pre- and post-tests for the Star Excursion Balance Test.

\begin{tabular}{|c|c|c|c|c|c|}
\hline \multirow{2}{*}{ Variables } & \multicolumn{2}{|c|}{ Experimental group } & \multicolumn{2}{|c|}{ Control group } & \multirow{2}{*}{ T sign } \\
\hline & Pre & Post & Pre & Post & \\
\hline Anterior & $95.16 \pm 8.55$ & $99.22 \pm 7.78$ & $90.75 \pm 7.05$ & $91.22 \pm 8.04$ & Sign. \\
\hline Anteromedial & $96.25 \pm 7.84$ & $100.22 \pm 7.26$ & $93.54 \pm 8.21$ & $95.07 \pm 7.12$ & Sign. \\
\hline Medial & $95.88 \pm 8.08$ & $102.43 \pm 8.63$ & $93.11 \pm 7.21$ & $94.76 \pm 9.13$ & Sign. \\
\hline Posteromedial & $100.42 \pm 6.84$ & $106.22 \pm 8.89$ & $99.25 \pm 7.26$ & $100.74 \pm 6.38$ & Sign. \\
\hline Posterior & $100.51 \pm 6.26 *$ & $107.16 \pm 8.79$ & $98.05 \pm 7.37$ & $100.31 \pm 7.28$ & Sign. \\
\hline Posterolateral & $94.61 \pm 8.08$ & $100.50 \pm 9.05$ & $92.62 \pm 7.65$ & $94.59 \pm 8.16$ & Sign. \\
\hline Lateral & $83.54 \pm 9.28$ & $91.34 \pm 0.05$ & $85.14 \pm 7.91$ & $86.78 \pm 9.06$ & Sign. \\
\hline Anterolateral & $85.24 \pm 8.11$ & $92.63 \pm 10.05$ & $81.02 \pm 7.47$ & $89.59 \pm 8.13$ & Sign. \\
\hline
\end{tabular}

Table 3 shows statistically significant differences in the post-measurements between the experimental and control groups in the Star Excursion Balance Test. 


\section{Discussion}

Based on the results of the present study, the t-test revealed statistically significant differences in the post-measurements for the experimental group in all of the physical variables. This improvement was attributable to the core training program and good planning of the functional strength training program. The training loads were regulated in a scientific manner that was appropriate for the age group. Training the research sample consisted of using a Swiss ball and seats Swedish as key parts of strength training to develop muscle strength. We took into account training the loads gradually during the application of the program by training different muscle groups, especially the muscles of the center, arms, and legs. We also concentrated on working on muscle groups during the bout and the accuracy of the selection. This functional strength training program led to improved strength and balance.

Dave (2003) suggested that the most important attribute of strength training is focusing on the center to emphasize the core, where the muscles of the center strong connecting the lower end party top. Additionally, strength training includes multidirectional movements and exercises that focus on one side, making it the single limb of the best exercises used to improve the strength of the muscles of the center (middle of the body), balance.

According to Fabio (2004) balance is a key element in athletics training, not only the balance between strength and flexibility or muscle working and non-working, but it also may believe that the means used, for example, stand on one foot and be able to move without the other members of the body to fall, a feature important in interactive training career.

Improved strength and distinctive as soon as Adams et al. (1992) confirms of the activity of reflection rubber allows for excellent power transfer speed to the same distinctive movements similar biomechanics that require a high capacity of the trunk, legs and show results when performing the broad jump.

The results of the present study are consistent with Cress et al. (1996), Yasumura et al. (2000), Marijke et al. (2004), and Cymara et al. (2004), in which core strength training was found to improve strength and balance as soon as distinctive.

The results of the Star Excursion Balance Test indicated significant main effects of time for all eight excursions. Unexpectedly, significant effects were found for all eight excursions. Some of these were more difficult than others (e.g., anterolateral excursion, posterolateral excursion, and lateral excursion) according to feedback from the subjects in both groups. Of the eight excursions, the diagonal excursions (i.e., anterolateral, posteromedial, posterolateral, and anterolateral) are the most important because human movement is multidimensional and multiplanar. All eight excursions were significant between the pre- and post-tests with regard to time, indicating that core stabilization training enhances multiplanar dynamic balance and movement, which can improve athletics performance.

Although the present study and previous studies have some basic similarities, the subject populations and designs of the studies were different. Piegaro (2003) studied 39 healthy subjects who were divided into four groups (i.e., core, core/balance, balance training, and control), whereas the present study used healthy tennis athletes and an agematched physically active control group. Swaney and Hess, (2003) used healthy subjects for their control group and swimmers, whereas Lewarchick et al. (2003) used healthy controls and football athletes.

Häkkinen, et al. (2005) performed a study showing just the opposite of Nelson's findings. They found that subjects who had resistance trained showed greater improvements in short- and long-term endurance compared to those who only endurance trained. Short-term endurance was 5-8 $\mathrm{min}$ to exhaustion and long term was maximal cycling time to exhaustion at $80 \% \mathrm{VO}_{2}$ max. It was hypothesized that resistance training increased short-term endurance performance by increasing high-energy phosphate and glycogen stores. Short-term endurance may have also been improved by increases in the fast twitch to slow twitch fiber area ratio. Long-term endurance performance was believed to have increased due to a delay in the recruitment of fast twitch fibers as a result of resistance training increasing maximum strength (Nelson, et al. 1990). Also, long-term endurance performance can benefit from resistance training not only by reducing large motor unit recruitment, but also by improving running or cycling economy. Similar to Hickson's findings (1980), Balabinis et al. (2003) recently reported that those who concurrently trained made greater gains in $\mathrm{VO}_{2}$ max than those who only endurance trained.

\section{Conclusion}

A 10-week core strength program can improve physical skills and dynamic balance in child athletes. 
References

1. Adams, K. O'Shea, J.P., O'Shea, K.L. The effects of six weeks of squat plyometric and squat plyometric training on power production, Journal of Applied Sport Sciences.1992;6(1):3641.

2. Arokoski J, Kankaanpaa M, Valta T, Juvonen I, Partanen J, Taimela S, Lindgren K, Airaksinen $O$. Back and hip extensor muscle function during therapeutic exercises. Archives of Physical Medicine and Rehabilitation,1999; 80(7): 842-850.

3. Axler CT, McGill SM. Low back loads over a variety of abdominal exercises: searching for the safest abdominal challenge. Med Sci Sports Exerc, 1997; 29 (6): 804-11

4. Behm DG, Anderson K, Curnew RS. Muscle force and activation under stable and unstable conditions. J Strength Cond Res , 2002; 16 (3): 416-22

5. Bergmark, A. Stability of the lumbar spine: a study in mechanical engineering. Acta Orthopaedica Scandinavica Supplementum, 1989; 230(60); 20-29.

6. Comerford MJ. Clinical assessment of stability dysfunction performance (online). (2008). Available

atURL:http://216.239.59.104/search?q=cache:sk MpsUpvPzIJ:www.kineticcontrol.com/documents /others/MicrosoftWord-

atingsystem0706.pdf+clinical+assessment+of +sta bility+dysfunction $\& h l=e n \& c t=c \ln k \& c d=2 \& g l=u k$

7. Cosio-Lima LM, Reynolds KL, Winter C, et al. Effects of physioball and conventional floor exercises on early phase adaptations in back and abdominal core stability and balance in women. $J$ Strength Cond Res,2003; 17:721-5

8. Cress ME, Conley KE, Balding SL, HansenSmith F, Konczak J. Functional training: muscle structure, function, and performance in older women, J Orthop Sports Phys Ther. 1996; 24(1):410

9. Cymara PK; David EK; Chris AM and Donna MS. Chair rise and lifting characteristics of elders with knee arthritis :functional training and strengthening effects, J American Physical Therapy Association, 2004; 83 (1)

10. Dave Schmitz. Functional Training Pyramids, New Truer High School, Kinetic Wellness Department , 14,2003
11. Fabio Comana - function training for sports, Human Kinetics: Champaign IL, 22,2004.

12. Lehman GJ. Resistance training for performance and injury prevention in golf. $J$ Can Chiropr Assoc, 2006; 50 (1):27-42

13. Lewarchik TM, Bechtel ME, Bradley DM, Hughes CJ, Smith TD. The effects of a seven week core stabilization program on athletic performance in collegiate football players. $J$ Athl Train, 2003 ;38S:S-81.

14. Lewis FM, Hawke JR. Orthopaedic treatments 1: the spine. Physiotherapy 1983; 69 (3): 76-7

15. Marjke J, Michael F, Bianca R. A Noncooperative Foundation of Core-Stability in Positive Externality NTU-Coalition Games, review to University of Hagen, Sweden,2004 .

16. Nadler SF, Malanga GA, Bartoli LA, Feinberg JH, Prybicien M, Deprince M. Hip muscle imbalance and low back pain in athletes: influence of core strengthening. Med Sci Sports Exerc, 2002 ; 34 (1): 9-16

17. Piegaro AD. The Comparative Effects of FourWeek Core Stabilization \& Balance- Training Programs in Semidynamic \& Dynamic Balance. Master's Thesis, Morgantown WV: West Virginia University,2003.

18. Pollock ML, Leggett SH, Graves JE, Jones A, Fulton M, Cirulli J. Effect of resistance training on lumbar extension strength. Am J Sports Med,1989 ; 17 (5): 624-9

19. Stanton R, Reaburn PR, Humphries B. The effect of short-term Swiss ball training on core stability and running economy. $J$ Strength Cond Res, 2004 ; 18 (3): 522-8

20. Swaney MR, Hess RA. The effects of core stabilization on balance and posture in female collegiate swimmers. J Athl Train,2003;38S:S-95.

21. Tse MA, McManus AM, Masters RS. Development and validation of a core endurance intervention program: implications for performance in college-age rowers. $J$ Strength Cond Res,2005 ; 19 (3): 547-52

22. Yasumura ST, Hamamura A, Ishikawa M, Ito H, Ueda Y, Takehara M, Miyaoka H, Murai C, Murakami S, Moriyama M, Yamamoto K, Yoshinaga T, Takeuchi T. Characteristics of functional training and effects on physical activities of daily living, Nippon Koshu Eisei Zasshi, 2000; 47(9):792-800 